\title{
Questions on notice to Falinksi Inquiry
}

Dr Cameron K. Murray

Research Fellow

Henry Halloran Trust, The University of Sydney

November 2021

\section{OECD chart}

The following chart was supplied as a piece of evidence in favour of the idea that more housing leads to lower prices.

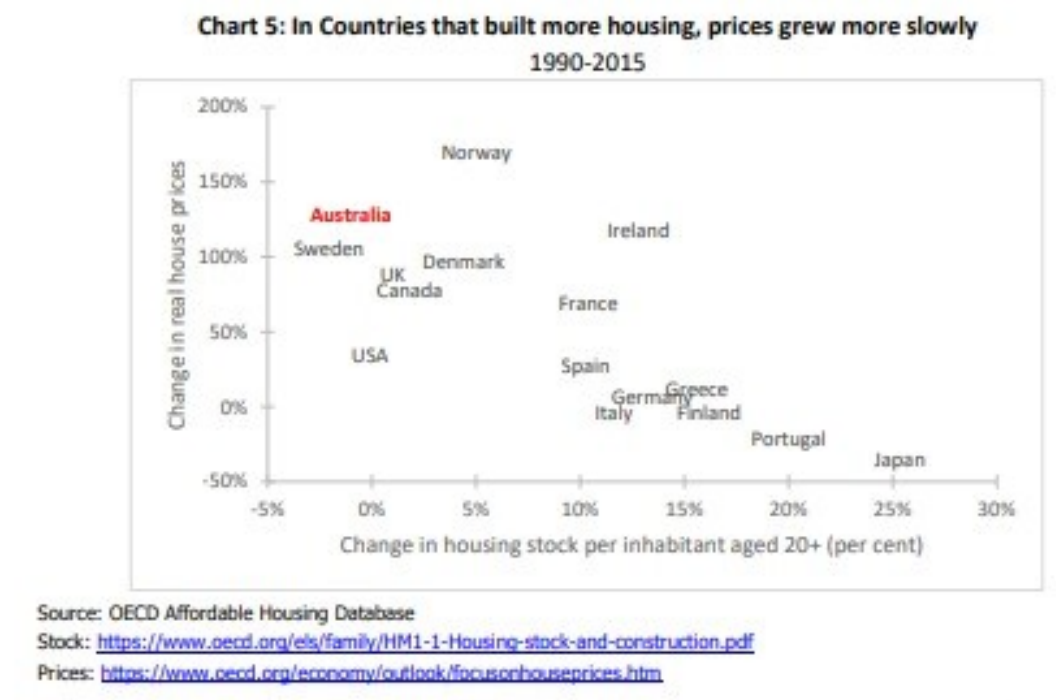

My response to this piece of evidence is as follows.

\section{Supply should lead to lower prices (and lower rents)}

First, the argument at stake is not whether more supply is better and will have some price effect. The argument at stake is that planning regulations are causing less supply than the private landowners want to provide given market conditions. Yes, more new dwellings for sale will reduce prices holding demand for homebuying constant. And yes, more dwellings in the stock of housing will reduce rents for a given level of demand. It is this very feedback of faster supply on prices that generates the limit to the rate at which the market will sell-if you flood the market you make less money because you reduce prices. 


\section{Cherry picking}

Second, there are at least four ways in which data choices generate the OECD chart with the negative relationship between dwelling stock and prices.

1. Selection of countries

2. Selection of time period

3. Selection of population measure (age 20+ population only)

4. Selection of price metric (inflation-adjusted asset price)

In Figure 1 is a replication of this chart using the latest OECD data since 2015 for all available countries and for all four different housing price metrics of

1. Nominal housing price growth (top left)

2. Real housing asset price growth (top right)

3. Change in the price/income ratio (bottom left)

4. Change in nominal rents (bottom right)

Only the change in real housing asset price has a statistically significant negative relationship. This indicates that mechanism generating this relationship is not that private markets delivered new housing faster, reducing both prices and rents in the process, otherwise rents and rent-topincome ratios would see the same pattern.

There could also be cherry-picking here too-after all, there is no reason that 2015-20 period across national aggregate data provides clear insights. Many countries have cycles in property asset markets that are out of sync.

Notably, Australia (AUS) had nearly the lowest real house price growth in this period, lower than even Japan.
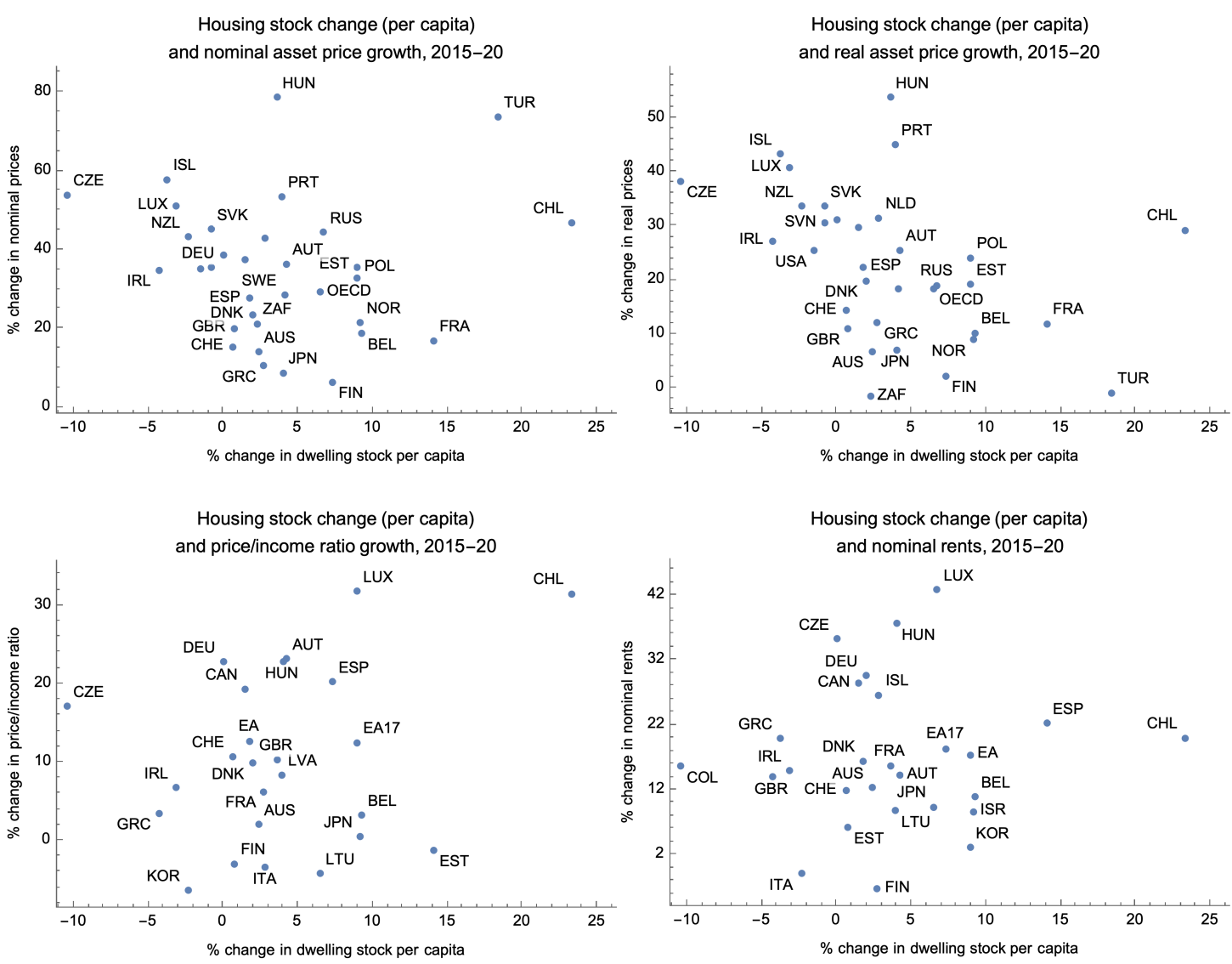

Figure 1: OECD measures of housing price and change in dwelling stock per capita 


\section{What developers say and do}

I was asked on notice to provide sources of evidence where developers had explained publicly that they choose not to flood the market with housing even if they can.

A first puzzle is that in their annual reports, listed companies like Stockland and Lendlease do not report that planning is inhibiting their ability to produce housing. In fact, in their 2021 annual report, Lendlease blamed themselves for not meeting the surge in market demand

The Australian Communities business has not been positioned to take full advantage of the favourable market environment over the last year. We expect sales to accelerate in FY22, boosted by the commencement of new projects. However, with the typical lag between sales and subsequent settlements, volumes are expected to remain below the annual settlement target of 3,000-4,000 lots. (p 16)

It is interesting to see them note that their own choices about positioning their projects were to blame for them not meeting their own conservative sales/settlement targets.

In 2011 Lendlease gained approval for a major master-planned subdivision at Yarrabilba in South East Queensland. At the time of approval there was much public discussion about a housing shortage and how this approval would help.

Now, ten years later, the project remains in the first stage only. Lendlease has held the bulk of the land vacant for a decade when these other stages could have been developed in parallel (by themselves of sold to another developer) rather than in sequence. Indeed, as they explain in Figure 2, they expect the project to last 30 years. Why not 20 years? Or 10 years?

\section{The Land Use Masterplan}

- $17,000+$ dwellings

- 45,000+ population

- Up to 20,000 jobs

- 100ha+ mixed industry and business

- Approx 50 ha retail, commercial and community

- Approx 75 ha education (up to 11 schools)

- Over $25 \%$ open space and a range of sport and recreation facilities

- 30 year project timeframe

\section{Lend Lease}

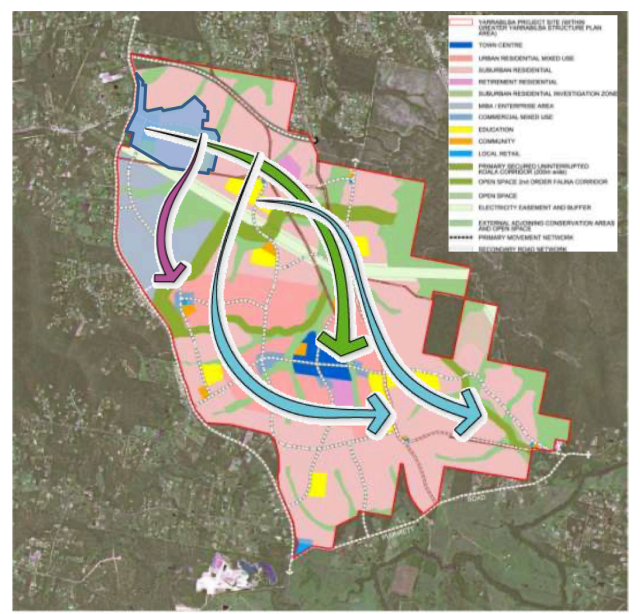

Figure 2: Yarrabilba masterplan details from Lendlease investor presentation from $2011^{1}$

Lendlease in their 2018 annual report noted that they are holding plenty of developable assets in "capital efficient structures" so that have "flexibility around delivery and timing, in line with market cycles". They said they could be "disciplined and patient with the pursuit of future opportunities". This does not sound a business that is developing as fast as possible within planning constraints.

${ }^{1}$ https://www.planning.org.au/documents/item/3031 


\section{Development Outlook}

The development pipeline which grew to $\$ 71.1$ billion, a rise of 44 per cent on the prior year, continues to provide significant earnings visibility. The pipeline comprises $\$ 55.9$ billion of urbanisation projects, $\$ 15.1$ billion of communities projects and telecommunications infrastructure.

The strong growth in the pipeline was driven by the four newly secured European projects that added a combined $\$ 21.9$ billion to the pipeline. Together with progress made on upscaling the 30 Van Ness project in San Francisco, we now have 18 major urbanisation projects across 10 gateway cities.

The Group has 13 major commercial buildings in delivery across 486,000 sqm with a total estimated end value of $\$ 8.3$ billion. We have 3,070 presold apartments for sale in delivery and 1,513 apartments for rent in delivery with a combined total estimated end value of $\$ 4.5$ billion.

In addition, the Group has a further estimated $\$ 44.4$ billion of secured urbanisation pipeline representing an estimated 25,917 apartment units and 1,516,000 sqm of commercial space. These projects are typically held in capital efficient structures, providing the Group with flexibility around delivery and timing, in line with market cycles.

The pipeline supports our target of delivering 1,000 to 2,000 apartment units per annum and commencing two to three commercial buildings per annum.

The origination focus in recent years has centred on our international operations with the year dominated by new projects secured in Europe. The majority of the urbanisation pipeline is now exposed to international gateway cities. We expect this to result in a greater contribution from these international cities over coming years.

The Communities pipeline consists of an estimated 52,333 lots. With an annual target of 3,000 to 4,000 completions, more than a decade of supply has already been secured.

The development pipeline provides long term earnings visibility and the flexibility to be both disciplined and patient with the pursuit of future opportunities. Diversification by geography and sector is expected to provide resilience through market cycles.

Figure 3: An explanation (highlighted) of patiently holding landbanks from Lendlease's 2018 annual report ( $p$ 75)

Stockland reported that their sales increased 54.2\% in FY2021 (up 75\% since 2019). How is that possible if planning is constraining housing supply? If the demand was there in 2019, could they have matched their 2020 sales? Or could they have increased sales by reducing prices?

They also note that they raised prices by $10 \%$ on average for their residential lots. Why? Are prices not cost-driven, as they claim? Why not increase the rate of sales rather than increase the prices? Doesn't it make more money to do that?

\section{Residential}

Demand for MPC to remain strong over FY22

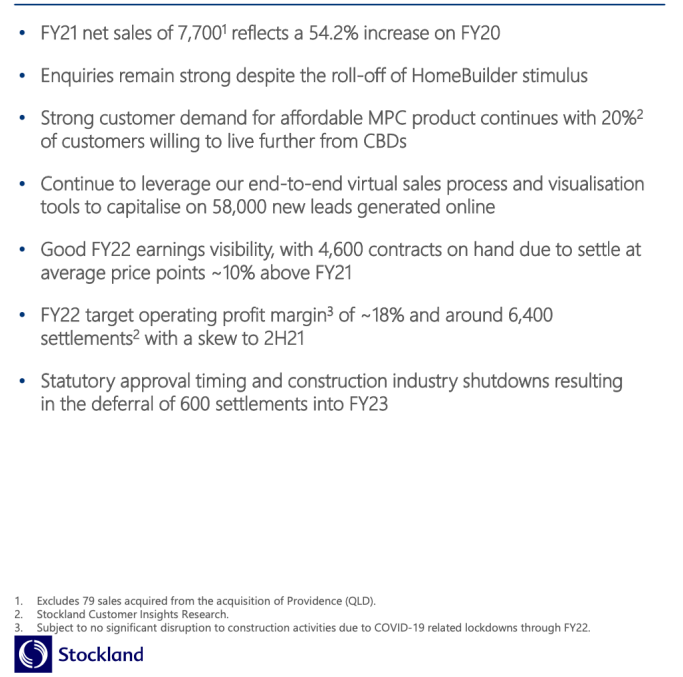

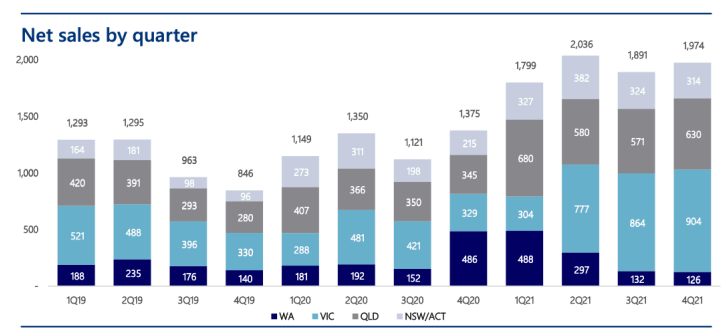

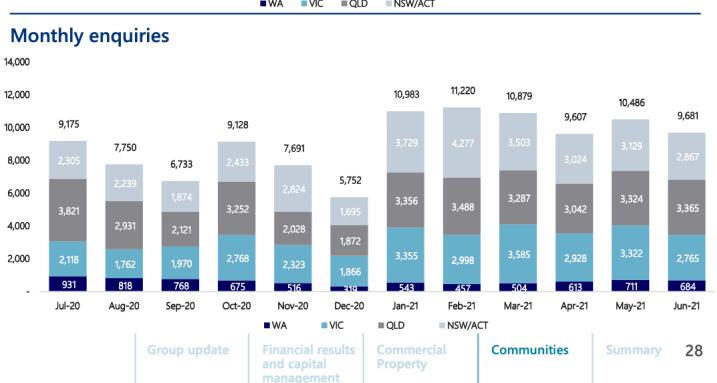

Figure 4: Stockland FY2021 residential results presentation 


\section{FINANCIAL REVIEW}

\section{Approval processes}

Urban Taskforce's Chris Johnson disagreed developers were dripfeeding stock and maintained "choked supply", caused by a planning system which was too "democratic", was causing price rises.

He agreed, however, there is a role for the government to lower the cost of land sales to developers in order to keep a lid on housing prices.

Developer Stockland said it has endeavoured to bring projects onto the market as quickly as it can clear complex approval processes, often through multiple local, state and federal authorities.

"It is costly and inefficient for developers to hold inactive land," Stockland residential chief executive Andrew Whitson said.

"We are now actively selling from 90 per cent of our projects and are working to achieve planning approvals on the remaining 10."

The housing situation was unlikely to improve after the Reserve Bank cut the cash rate to a historic low of 1.5 per cent on Tuesday and after the major cities posted another housing price rise for July as indicated by Corelogic.

Su-Lin Tan reported on housing, commercial real estate and property finance. She also covered China and Asian business, trade and politics. Connect with Su-Lin on Twitter.Email Su-Lin at stan@afr.com.au

Figure 5: Quote from Stockland in 2016 AFR article 2

In 2016 Andrew Whitson, CEO of Stockland Communities, told journalist Su-Lin Tan that is it "costly and inefficient to hold inactive land". In that same year, the Director's report noted that they would "maintain an optimal pipeline" and "actively manage the portfolio to improve returns" (see Figure 6) This sounds like their landbank is actually not costly to hold, but a key part of their asset portfolio. Indeed, though it was noted that $90 \%$ of projects were "active", these projects are estimated to produce 58,800 housing lots, yet they were selling only 6,000 per year at the time (see Figure 7). That would take 10 years to sell. If it were truly costly to hold so much land, they could sell faster or sell parts of projects to other developers and reduce this massive landbank.

${ }^{2}$ https://www.afr.com/property/the-free-market-has-failed-to-provide-affordable-housing-insydney--melbourne-20160802-gqixlw 
Residential strategic priorities

The Residential business is making good progress on its plans to make the portfolio more resilient and profitable in the future by continuing to focus on:

(1) Reshaping the portfolio - actively manage the portfolio to improve returns and achieve and maintain an optimal pipeline with a preference to acquire land on capital efficient terms. We continue to make good progress in activating our land through the launch of new projects and working through low margin and impaired stock.

(2) Improving efficiency - continue to manage costs. Project management has been embedded into the business and is driving significant cost savings.

(3) Delivering revenue growth - increase revenue by creating a better community value proposition that drives high customer referrals and broaden market reach through a medium density/built form offering.

Figure 6: Stockland's 2016 Director's report about maintaing "an optimal pipeline" (p 13)

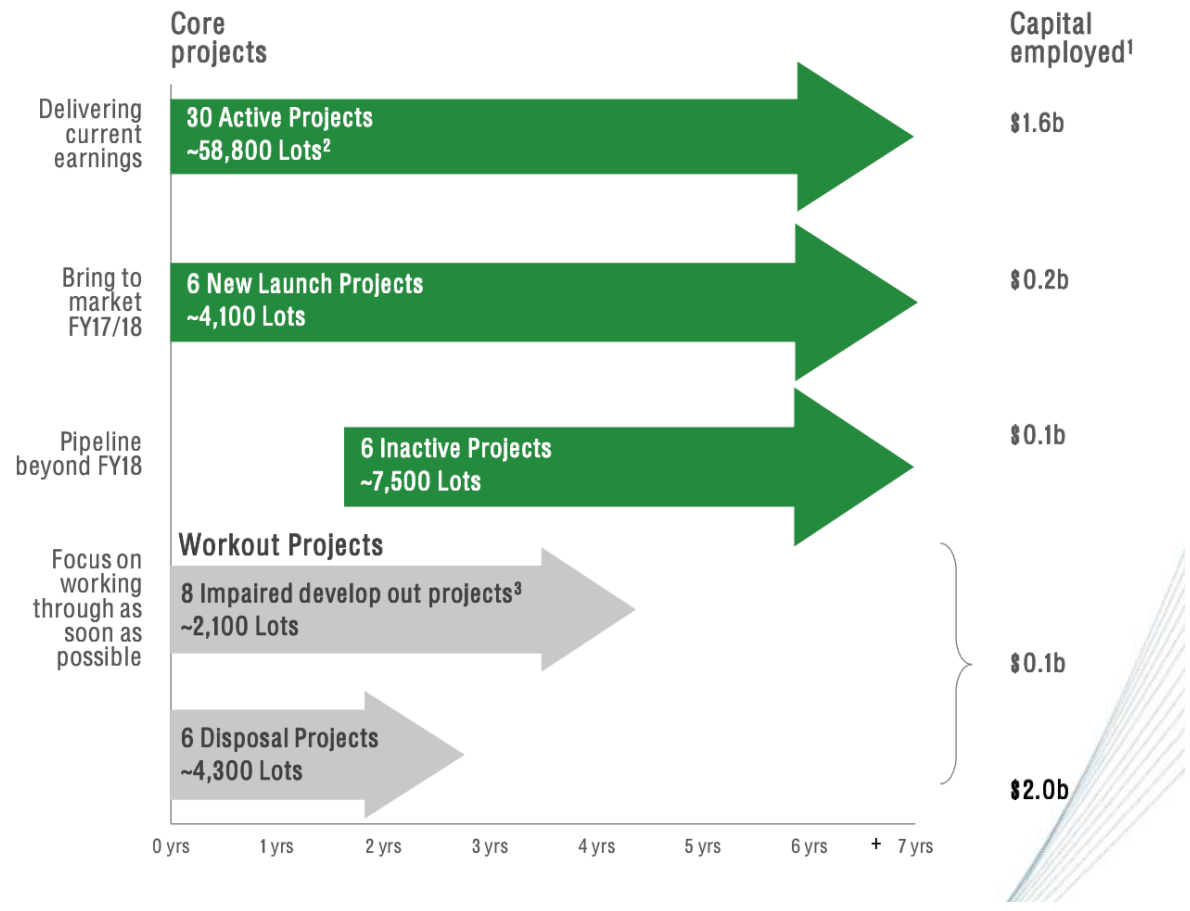

Figure 7: Stockland's 2016 residential pipeline

I also gave evidence to the inquiry that build-to-rent (BTR) property managers also have the same incentives to regulate the rate at which they rent out dwellings. The Smith Collective on the Gold Coast is Australia's first major BTR project and was the former Commonwealth games athlete's village. The project has 1,251 one-, two- and three-bedroom dwellings, all of which were completed prior to the 2018 Commonwealth Games.

When I enquired about the project progress in January 2021, I was provided the following response (Figure 8 ), which noted how the project was on a staged releases to avoid flooding the rental market.

During the 2019-20 period when this project had hundreds of completed dwellings sitting unoccupied, the rental vacancy rate $^{3}$ in the regions was between $2 \%$ and $3 \%$ and has since fallen to below $1 \%$.

\footnotetext{
${ }^{3}$ Measured as the number of properties advertised for rent over a calendar month as a share of total estimated rental properties in the region. https://sqmresearch.com.au/graph vacancy.php?sfx=\&region=qld\%3A\%3AGold+Coast+North\&t $=1$
} 
To: Cameron Murray

Good Morning Cameron,

Thank you very much for your email.

I would be happy to help with some publicly available information and statistics to assist with your research.

\begin{abstract}
Since opening in 2018 the precinct has been on a staged release strategy so as to not flood the rental market. We were impacted somewhat during COVID last year however leasing has continued to remain steady and with the Gold Coast rental demand, we have seen quite a dramatic increase in enquiries and applications over the past 3 months. The precinct is now just over $70 \%$ occupied with the release of two new buildings just this week. Leaving only 1 empty building left to be released which will be staged for around the middle of the year. In conjunction with the leasing of the apartments is the leasing of our retail space in the centre of our precinct which will also ramp up this year.
\end{abstract}

We have just over 1800 residents now therefore it's really taking shape as a lovely and friendly community where residents can be comfortable knowing it's a Build to Rent community where there is no risk of their homes being sold.

Unfortunately we don't have any publicly available surveys at this stage.

Kind regards,

Figure 8: Email from BTR manager (14 Jan 2021)

\title{
Questions for developers
}

I was also asked on notice to suggest developers to bring as witnesses before the inquiry and what questions to ask to determine whether they limit the rate they develop based on market conditions or planning regulations.

People who have insights into the question of market limits to developer would include the heads of the communities or residential divisions of major listed Australian housing developers like Stockland, Lendlease, PEET, Mirvac, Frasers, and private developers like Meriton. Key personnel from JLL who manage the Smith Collective BTR project would be useful.

Questions to put to them would centre on:

1. If a new competitor established themselves besides your major residential projects and sold similar dwellings for $25 \%$ less than what you sell them for, would that be good or bad for your business financially? Good, or bad?

2. Yet is it not your argument, or at least that of many property lobby groups, is that rezoning will lead to lower housing prices, and the mechanism will be through more competition from cheaper competitors?

3. Why do you target such small rates of housing completion?

4. Would you sell faster if you had an inactive project rezoned?

5. Do you think that rezoning in Australia will lead to dwellings prices more than $20 \%$ lower than they are now?

6. If holding big landbanks is costly, when demand falls, why don't you reduce prices sufficiently to keep the sales rate up to its previous level?

7. How much are your landbanks worth as undeveloped assets?

8. If dwelling prices fell $20 \%$, how much would that affect the value of you balance sheet?

9. Are prices set by input costs, or by the market? I.e. Do you increase prices when the market rises, regardless of whether you had additional costs? (prices seem unrelated to costs?) 